\title{
Pharmaciana
}

Vol.11, No.1, March 2021, Page. 25-38

ISSN: 2088 4559; e-ISSN: 24770256

DOI: $10.12928 /$ pharmaciana.v11i1.18468

\section{Distribution of cytochrome P450*4 (CYP2A6*4) allele gene among Javanese Indonesian T2DM patients}

\author{
Christine Patramurti*1, Dita Maria Virginia ${ }^{2}$ \\ ${ }^{1}$ Departement of Pharmaceutical Chemistry, Faculty of Pharmacy, \\ Sanata Dharma University \\ Paingan, Maguwoharjo, Depok, Sleman, Yogyakarta. \\ ${ }^{2}$ Departement of Pharmacology and Clinical Pharmacy, Faculty of Pharmacy, \\ Sanata Dharma University \\ Paingan, Maguwoharjo, Depok, Sleman, Yogyakarta.
}

\begin{abstract}
Smoking had been increasing the risk factor of type 2 diabetes mellitus (T2DM), both active and passive smokers, which is caused by nicotine contained in cigarettes. Nicotine has metabolized by cytochrome p450 2a6 (CYP2A6) enzyme coded by the CYP2A6 gene. This gene was a high polymorphism that is the CYP2A6*4 allele gene was inactive. Thus, our objective was to describe the CYP2A6*4 allele gene among active and passive Javanese smokers with T2DM. From this crosssectional study, we identified this allele gene among 46 of the adults with T2DM, which were consist of 23 active smokers and 23 passive smokers. The CYP2A6*4 allele gene identification has done using polymerase chain reaction (PCR) methods. The CYP2A6*4 allele frequency was analyzed to describe the distribution of this allele among the participants. This study supports the hypothesis that smoking, including cigarette smoke, was an environmentally modifiable risk factor for developing T2DM. Based on our result, the allele frequency among the participants was $42.39 \%$. A high frequency of the CYP2A4 allele gene among the participants was indicating that the CYP2A4 allele gene was also the other risk factor in developing T2DM.
\end{abstract}

Keyword: Smoking, Polymorphism, CYP2A6*4, Type 2 Diabetes Mellitus

*Corresponding author:

Christine Patramurti

Department of Pharmaceutical Chemistry, Faculty of Pharmacy, Sanata Dharma University

Kampus III USD, Paingan, Maguwoharjo, Depok, Sleman, Yogyakarta.

Email: patra@usd.ac.id 


\section{INTRODUCTION}

As stated by the American Diabetes Association (Association, 2011), diabetes mellitus was one of the metabolic diseases characterizing by hyperglycemia that appears due to malfunctions of insulin secretion, insulin resistance, or both. It is a chronic disease that refers to the body's inability to metabolize carbohydrates, fats, and proteins. Furthermore, this condition was leading to hyperglycemia. Diabetes mellitus disease has been considering to be a disease found in adults. Nevertheless, in the past 20 years, it has been an increase in the prevalence of diabetes in children and young people. As reported in Indonesia's Primary Health Research (R.I., 2018b), known as Riskesdas, Diabetes Mellitus prevalence in Indonesia has increased from 6.9\% in 2013 to $8.5 \%$ in 2018.

Diabetes is one of the underdiagnosed diseases. It has been estimating that $30 \%$ of people who suffered from it are often unaware of this disease. Moreover, approximately $25 \%$ of them have had microvascular complications after being diagnosed with T2DM. The most common type of diabetes found among adults was type 2 diabetes mellitus (T2DM). It has been estimating that more than $90 \%$ of all diabetes cases are T2DM. The prevalence of diabetes mellitus in urban Indonesia was $6.2 \%$. Some researchers predicted more than half of diabetes cases in Indonesia were not diagnosed, especially among young people. According to the International Diabetes Federation (IDF), in 2017, 163 million people in Indonesia have been living with T2DM; by 2045, this will rise to 212 million.

T2DM was also commonly known as the silent killer disease. At first, people living with T2DM frequently have no symptoms and were usually detected after the age of 40 years or more. However, it was also possible that someone was getting T2DM before the age of 40 years. Once a person has been diagnosed with T2DM, it gradually can affect all the body organs. Furthermore, it would cause various damage and dysfunction of several organs, especially the eyes, kidneys, nerves, heart, and blood vessels. T2DM development has been relating to several risk factors, such as age, ethnicity, obesity, family history, physical activity, lifestyle behavior, and cigarette smoking. Some studies suggest that poor smoking behavior has been associating with chronic complications of T2DM compared to nonsmokers (Hilawe et al., 2015; Hong et al., 2018; Kowall et al., 2010; Liu et al., 2018; Nilsson et al., 2014). Nicotine, the main bioactive compound contained both in cigarettes and tobacco smokes, was considered as the most accountable for increasing blood glucose levels (Bajaj, 2012; Borowitz and Isom, 2008; Xie et al., 2009).

Nicotine was inactivated to cotinine by CYP2A6, an enzyme coded by the CYP2A6. The CYP2A6 gene was highly polymorphic and had detected among various ethnicities who are indicating by a broad interethnic variability smoking behavior of the allele carrying persons. The wild-type allele was CYP2A6*1, the whole gene deletion that causing loss of enzymatic activity was CYP2A6*4. This gene was frequently found in the Asian population and corresponded to both slow and poor nicotine metabolizers (Tanner and Tyndale, 2017). Thus, slow and poor nicotine metabolizers will inactivate nicotine more slowly than normal metabolizers. It is leading to a high risk of developing diabetes.

Indonesia was one of the countries with a high level of cigarette consumption (Barber et al.,2008). To date, public awareness of the smoking risks in Indonesia still has no attention yet including diabetes risk among smokers. Both smoking and diabetes could damage body cells and organs. Smokers living with diabetes have higher risks for severe health problems, including cardiovascular and kidney disease, retinopathy, and peripheral neuropathy (Campagna et al., 2019). In our previous study, we revealed that there was a highly frequent CYP2A6*4 among Javanese Smokers and they were identified as nicotine slow metabolizers (Patramurti et al., 2015). Therefore, in this study, we learned the allele frequencies of the CYP2A6*4 genes among T2MD patients to describe the CYP2A6*4 effect on T2DM as a potential risk factor in developing T2DM. 


\section{MATERIALS AND METHODS \\ Materials}

The Ron's Blood and Cell DNA Mini Kit reagents were obtained from Bioron GmbH

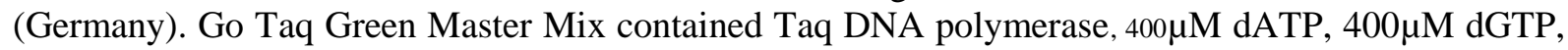
$400 \mu \mathrm{M}$ dCTP, $400 \mu \mathrm{M}$ dTTP, $3 \mathrm{mM} \mathrm{MgCL} 2$, Buffer (pH 8.5), and Nuclease-Free Water obtained from Promega Corporation (USA). AccuBandTM 100 bp+3K DNA Ladder II obtained from SMOBIO Technology, Inc. (Taiwan). All primers used were synthesized by Vivantis Technology Sdn. Bhd. (Malaysia).

\section{Methods}

This research was carried out in five Primary Health Care, known as Puskesmas, located in Sleman Regency, Special Region of Yogyakarta. It is an observational study with cross-sectional design and purposive sampling. The study population was patients, who had the same symptoms associated with diabetes, including polyuria, polydipsia, polyphagia, and tiredness. They were men, and women, aged 30-80 years and visited the five Puskesmas above during April-June 2020. Base on their symptoms, the baseline clinical trial was done, including assessment of random plasma glucose, fasting glucose levels, HbA1c levels, and completion of questionnaires.

A standard questionnaire to each participant has been using to obtain information about demographics, socioeconomic status, smoking habits, physical activity, and medical history. Smoking status has been classifying into two categories. It was never and current smokers. Some questions were collected to find out information about smoking status, including age at starting and quitting smoking, type of tobacco, the number of cigarettes smoked per day (CPD), and duration of cigarette smoking (Heatherton et al., 1991).

A standard questionnaire to each participant has been using to obtain Only participants who have filled out the questionnaire and signed informed consent were eligible to participate in this study. The study has approved by the Ethics Committees of Medical Research Duta Wacana University (Yogyakarta, Indonesia) with ethical clearance No. 1199/C.16/FK/2020. All data collected was confidential because these documents have managed anonymously, so these data collected could not be recognized.

Blood samples were taken from the subject veins and collected in a vacutainer containing EDTA (1.8 mg / mL blood). The blood samples have used as a material for DNA isolation using Ron's Blood and Cell DNA Mini Kit reagents. The polymerase chain reaction (PCR) method has been using to analyze the CYP2A6*4 allele gene in isolated DNA. The sequence of the PCR primer forward: 5'CCT CAT CAC ACA CAA CTT CCT C-3'; reverse primer (wild type): 5'-CGC AGG TAC TGG GTG CTT GGT AG-3'; (mutant): 5'-TGC AGG TAC TGG GTG CTT GGT AG-3'].

A reaction solution of $25 \mu \mathrm{L}$ contained Promega Go Taq Green Master Mix (12.5 $\mu \mathrm{L})$, forward primer $(1.25 \mu \mathrm{L})$, reverse primer $(1.25 \mu \mathrm{L})$, isolated DNA $(5.0 \mu \mathrm{L})$, and Nuclease-free Water $(5.0 \mu \mathrm{L})$. The PCR analysis carried out under the following conditions: after initial denaturation at $95{ }^{\circ} \mathrm{C}$ for 5 min, 30 cycles of denaturation at $98{ }^{\circ} \mathrm{C}$ for $20 \mathrm{sec}$, annealing at $64{ }^{\circ} \mathrm{C}$ for $15 \mathrm{sec}$, and extension at $72^{\circ} \mathrm{C}$ for $30 \mathrm{sec}$ were performing. Finally, the reaction was finished by a final extension at $72{ }^{\circ} \mathrm{C}$ for 5 min. The $3.0 \mu \mathrm{L}$ of the amplified PCR product was identified by electrophoresis on $1.5 \%$ agarose gel and documented using a Polaroid camera. The PCR products of CYP2A6*1 and CYP2A*4 allele gene were detected at 350-bp.

\section{Data Analysis}

The 95\% confidence intervals were calculated for all observed allele frequencies. The HardyWeinberg equation was used to calculate the expected genotype frequencies from the allele frequency among the participants $(\mathrm{p} 2+2 \mathrm{pq}+\mathrm{q} 2=1)$. The qualitative analysis was used to illustrate the effect of CPY2A6 polymorphism, CYP2A6*1 and CYP2A6*4 alleles, on T2DM risk factor among the subjects. 


\section{RESULT AND DISCUSION}

Today, Indonesia was undergoing a pattern changing in diseases that are often called epidemiological transitions marked by increased mortality and illness due to non-communicable diseases (PTM) such as stroke, heart disease, diabetes, and others. This study aimed to evaluate the effect of CYP2A6 polymorphism, especially the CYP2A6*4 allele gene and smoking behavior on the risk of T2DM among diabetic patients in primary health care, known as Puskesmas, located in Sleman Regency, Special Region of Yogyakarta. It is an observational study using a cross-sectional design. The subjects participating in this study were T2DM patients from those five Puskesmas. This T2DM disease was the seventh leading of ten non-communicable diseases commonly suffered by people in this regency. It has been estimating that 29,079 cases of diabetes patients have been founding in this area (R.I., 2018b).

All the subjects participating in this study were new patients who have never been diagnosed with diabetes. They have been recruiting from April-June 2020. Early identification for each subject has been determined based on their symptoms that are leading to diabetes. They are polyuria, polydipsia, polyphagia, and tiredness. Further assessments have been carrying out to establish the diagnosis. The examination of random plasma glucose and HbA1c levels has been carrying out to establish the diagnosis. We defined participants as having T2DM if they met the following criteria: the blood fasting glucose level was more than $125 \mathrm{mg} / \mathrm{dL}$, and the HbAlc concentration was more than 6.5 (ADA, 2014). Based on these examinations, a total of 75 patients were diagnosed with T2DM, which are consisting of 52 females and 23 males. Based on this data, there were saw those female sufferers were greater than males. It was in line with documents presented in Riskesdas (R.I., 2018b), which was the number of Indonesian females living with T2DM was greater (1.8\%) than males $(1.2 \%)$. Some other studies have also revealed that females have a higher risk of developing diabetes than males. It was due to the female's physical activity was lower than in males, resulting in body fat accumulation that triggers obesity (Abdullah and Mansour, 2020; Agbogli and Annan, 2017; Asiimwe et al., 2020; Eze et al., 2014). Furthermore, it is associated with an enhanced risk of developing insulin resistance and ultimately causing the T2DM (Mary et al., 2014). The other risk factors are age, T2DM family history, physical activity, and smoking behavior.

Of the total 75 patients suffering from T2DM, 46 patients have been recruiting to participate in this study, consist of 23 subjects who were active smokers and 23 who were passive smokers. Therefore, to investigate more information about the participants, they were given several questions related to diseases and smoking behavior. Several studies have shown that a family history of diabetes was one of the main risk factors for a person developing T2DM (Cederberg and Stan, 2014; Sakurai et al., 2013; Scott et al., 2014; Zhao et al., 2017). Some studies have also suggested that smoking behavior could increase the T2DM risk factors, neither active nor passive smokers (Hackethal, 2015; Hong et al., 2018; Kowall et al., 2010; Liu et al., 2018; Nilsson et al., 2014; Yeh et al., 2010). The following table represents the subject characteristic (Table 1). 
Tabel 1. Subject Characteristic who diagnosed T2DM and participated in this study

\begin{tabular}{|c|c|c|c|c|c|}
\hline \multirow{2}{*}{ Characteristic } & \multicolumn{2}{|c|}{ Male } & \multicolumn{2}{|c|}{ Female } & \multirow{2}{*}{$\begin{array}{c}\text { Total } \\
(\%)\end{array}$} \\
\hline & Number & $\begin{array}{c}\text { Percentage } \\
(\%)\end{array}$ & Number & $\begin{array}{c}\text { Percentage } \\
(\%)\end{array}$ & \\
\hline \multicolumn{6}{|l|}{ Age } \\
\hline$\leq 45$ & 1 & 4.3 & 2 & 8.7 & 6.5 \\
\hline$>45$ & 22 & 95.7 & 21 & 91.3 & 93.5 \\
\hline \multicolumn{6}{|l|}{ Smoking status } \\
\hline Smokers & 23 & 100.0 & 0 & 0.0 & 50.0 \\
\hline Non Smokers & 0 & 0.0 & 23 & 100.0 & 50.0 \\
\hline \multicolumn{6}{|l|}{ Smoking years } \\
\hline$\leq 25$ & 3 & 13.0 & 0 & 0.0 & 13.0 \\
\hline$>25$ & 20 & 87.0 & 0 & 0.0 & 87.0 \\
\hline \multicolumn{6}{|l|}{ CPD } \\
\hline$\leq 10$ & 4 & 17.4 & 0 & 0.0 & 17.4 \\
\hline $11-20$ & 17 & 73.9 & 0 & 0.0 & 73.9 \\
\hline $21-30$ & 2 & 8.7 & 0 & 0.0 & 8.7 \\
\hline Family History & 6 & 26.1 & 7 & 30.4 & 28.3 \\
\hline No Family History & 17 & 73.9 & 16 & 69.6 & 71.7 \\
\hline
\end{tabular}

Age was also a risk factor for someone developing T2DM. The American Diabetes Association (ADA) suggests annual diabetes screening tests after people reach 45 years of age. Based on Table 1 above, $93.5 \%$ of the subjects were more than 45 years old, and only $6.5 \%$ of patients had aged less than 45 years. Several studies have shown that the possibility of developing the T2DM increases significantly after 45 years of age (Alva et al.,2017; Kirkman et al.,2012; Nguyen et al., 2012; Sattar et al., 2019). Primary Health Research Indonesia has reported that T2DM accounted for 90-95 percent of diagnoses of diabetic adults in Indonesia, with the largest number of T2DM sufferers are aged range 55-64 years and 65-74 years. It has been estimating 30\% population in Indonesia has lived with diabetes, and $25 \%$ of those people have suffered a microvascular complication (R.I., 2018b). The T2DM was one of the underdiagnosed diseases. It commonly goes undiagnosed for several years because hyperglycemia grows slowly, and at initial periods it was frequently not severe enough for the patient to detect the common T2DM symptoms. Moreover, the average delay from onset to diagnosis was estimated to be 7th years (Buell et al., 2007).

Table 1 shows that $71.7 \%$ of the subjects did not have a family history of diabetes. It indicates that the development of diabetes in patients has been mainly causing by the environment or their lifestyle, including physical activity and smoking behavior. Several studies have shown that being physically inactive will lead to being overweight, which is a trigger for diabetes risk factors (Binh and Nhung, 2015; Cornier et al., 2005; Hu, 2011; Liu et al., 2000; Schulze et al., 2015). The other studies have revealed that smoking activity, an environmental factor, have also increased the risk of incident T2DM (Hackethal, 2015; Hong et al., 2018; Jee et al., 2010; Liu et al., 2018).

In this study, all the smokers were male, while all the non-smokers were female. There have been estimating that $68.1 \%$ of active smokers in Indonesia were adult males (Zheng et al., 2018). There have been estimating that 96 million women and children in Indonesia are passive smokers who have been routinely exposing to secondhand smoke (Barber et al., 2008; R.I., 2018a). Some other studies have shown that passive smokers also have a high risk for developing T2DM even in those who are never themselves active smokers (Eze et al., 2014; Wang et al., 2013; Wei et al., 2014). 
Therefore a high percentage of subjects did not have a T2DM family history in this study might also be caused that they are passive smokers. Hackethal (2015) has indicated that active smokers had a $37 \%$ increased risk for T2DM, otherwise former smokers had a $14 \%$ increased risk, and people who have been exposing to secondhand smoke had a $22 \%$ higher risk for developing T2DM.

In the previous study, we revealed that smoking behavior could affect glycohemoglobin levels (HbA1c) (Patramurti and Fenty, 2020). There has been demonstrating that the number of cigarettes smoked, and the length of smoking activity will increase the HbA1c level that leading to a high risk for suffering T2DM. Smoking more than 20 cigarettes a day almost doubles a smoker's odds of getting T2DM. Furthermore, we indicated that the prediabetes condition would arise at a minimum CPD of 20 cigarettes and a minimum smoking duration of 25 years. While, the diabetes condition will appear at a minimum CPD of 20 cigarettes with a minimum smoking duration of 29 years (Patramurti and Fenty, 2020). Based on the data presented in Table 1 above, it saw that $91.3 \%$ (17.4\% smoked $<10$ and 93.9\% smoked 11-20) of participants have only smoked less than 20 cigarettes per day. However, $87 \%$ of them have smoked for more than 25 years, but only $13 \%$ of them have had a smoking activity for less than 25 years. The participants who smoked less than 25 years have a family history of diabetes. Therefore, smoking activity would accelerate the development of T2DM on the subjects. Some other participants straight continue to smoke, although they have been diagnosed with T2DM and did not seem to care about the hazard of smoking on diabetes complications. Chang (2012) have reported that smoking could worsen the illness harder to manage and would increase the incurring some severe diabetes complications, including heart and kidney disease, retinopathy, peripheral neuropathy, heart disease, stroke, and circulation problems.

Many diabetic patients continue to smoke despite the hazard of smoking on diabetes complications and mortality. Nicotine, the active compound in cigarettes, was considered as the most risk factor responsible for developing T2DM in smokers, both active and passive smokers. Nicotine can trigger insulin resistance and inhibit insulin secretion. According to Bajaj (2012) and Bergman et al. (2012), the interaction of nicotine to nicotinic acetylcholine receptors (nAChRs) would activate the mammalian target of rapamycin (mTOR / p70S6) and would cause phosphorylation of insulin receptor substrate 1 (IRS-1 / Ser 636). So, the long term of cigarette smoke exposure in active and passive smokers would be increasing of IRS-1/Ser 636 phosphorylation and could be leading to impaired insulin receptors and develop insulin resistance. Another study has reported that the interaction of nicotine with nAChRs in $\beta$ cells pancreas in the long term would cause the increased apoptosis of pancreatic $\beta$ cells so the insulin production would be disrupted and resulting in high blood glucose levels (Morimoto et al., 2013). There has been estimating that approximately $80 \%$ of inhaled nicotine were inactivated into cotinine and trans-3-hydroxycotinine by the CYP2A6 enzyme coded by the CYP2A6 gene. This gene has a high polymorphism with the inactive allele gene was CYP2A6*4 that would be reducing enzyme activity and ultimately resulting in decreased nicotine metabolism.

The CYP2A6 * 4 allele gene identification in this study was carried out by the PCR method using whole blood as material for DNA isolation. The forward and reverse primer used in this study have designed specifically anneal to CYP2A6*1 and CYP2A6*4 allele genes with a sequence located in exon 10643 to 10993 and produced an amplicon of 350 bp length. The forward primer could anneal to CYP2A6*1 and CYP2A6*4 allele genes. On the other hand, we used two types of reverse primer, the wild type reverse primer could only anneal to CYP2A6*1 and the mutant reverse primer could only anneal to CYP2A6*4. These two reverse primer have only one different nucleotide, therefore, the PCR product for allele* 1 and allele*4 was having the same size molecule weight ( $350 \mathrm{bp}$ ).

Pharmaciana Vol. 11, No. 1, March 2021, Page. 25 - 38 


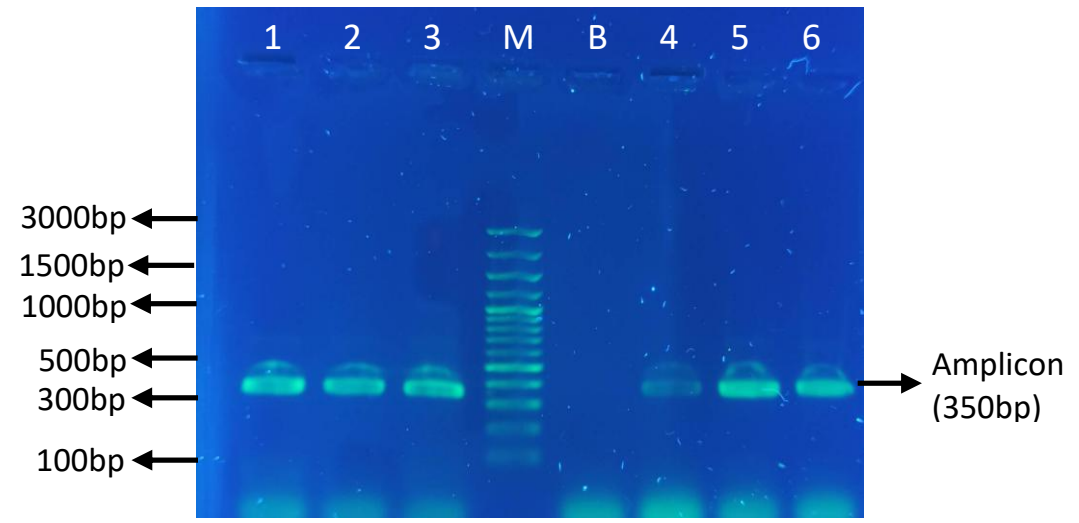

Figure 1. CYP2A6*4 allele gene amplicon identified using agarose 1,5\% and detected under UV transilluminator (M: Marker (100 bp+3K); B: Blank; 1-3: CYP2A6*1 Amplicon; 4-6: CYP2A6*4 Amplicon)

The following table has described the CYP2A6*4 allele gene frequency identified among the subjects who have participated in the study.

Table 2. Genotype dan CYP2A6*4 allele frequency among participants

\begin{tabular}{lccc}
\hline \multirow{2}{*}{ Genotype } & \multicolumn{2}{c}{ Frequence } & \multirow{2}{*}{ Total } \\
\cline { 2 - 3 } & \multicolumn{2}{c}{ Number of Participant (n=46) } & \\
\cline { 2 - 3 } & \multicolumn{2}{c}{ Non smokers (23) } & Smokers (23) \\
\hline CYP2A6*1/CYP2A6*1 & $56.52 \%(13)$ & $30.13(9)$ & $47.83(22)$ \\
CYP2A6*1/CYP2A6*4 & $34.78 \%(8)$ & $47.83 \%(11)$ & $41.30 \%(19)$ \\
CYP2A6*4/CYP2A6*4 & $8.70 \%(2)$ & $13.04 \%(3)$ & $10.87 \%(5)$ \\
Allele & \multicolumn{2}{c}{ Number of Allele (n=92) } & \\
CYP2A6*1 & $36.96 \%(34)$ & $33.70 \%(31)$ & $57.61 \%(65)$ \\
CYP2A6*4 & $13.04 \%(12)$ & $16.30 \%(15)$ & $42.39 \%(27)$ \\
\hline
\end{tabular}

As described in Table 2, it appears that the CYP2A6*4 alleles frequency among the participants is $42.39 \%$. All of the subjects who participated in this study are Javanese, so this result was consistent with our previous studies that were resulted in the allele frequency of the CYP2A6*4 among Javanese smokers was high (Patramurti et al., 2015). Tanner and Tyndale (2017) have also noticed that among Asian populations, the allele frequencies of an inactive CYP2A6 gene were higher compared to Caucasians. According to Mwenifumbo et al. (2008), smokers with the CYP2A6*4 allele gene have been considering as poor or slow metabolizers. Therefore, nicotine metabolism in a smoker who has the CYP2A6*4 gene allele would be slower compared to normal/fast metabolizers. Thus, CYP2A6 slow metabolism is associated with decreased nicotine metabolism and increasing the nicotine plasma level. Liu et al. (2011) have reported that slow or poor metabolizer smokers would have been more susceptible to suffering T2DM compared with fast or intermediate metabolizer smokers.

All the participants who are smokers in this study have been smoking cigarettes for more than 20 years. Therefore, all of them have been exposing to nicotine for a long time. The other that all the participants, both active and passive smokers, are adult and elder, with the average age is 54 years. So, all of the participants have been exposing to cigarette smoke for a long time. Maddatu et al., (2017) have described that in a cohort study among females who are never smoke, exposure to secondhand smoke may be a risk factor for the development of T2DM. The exposure to nicotine in the long term in people would cause an accumulation of nicotine in the blood and ultimately increase the risk of 
T2DM. It was mainly for slow metabolizers, both in active and passive smokers, due to the pancreas exposed to greater circulating levels of nicotine that may contribute to apoptosis of islet $\beta$-cells and causing the decreasing insulin.

Another potential mechanism that was underlying the development of T2DM among smokers, both active and passive smoker, related to the CYP2A6*4 allele gene, was a tobacco-specific nitrosamine (TSNA) contained in cigarette smokers. There are some TSNA, pre-carcinogen compounds contained in both smoked and smokeless tobacco products, including 4(methylnitrosamino)-1-(3-pyridyl)-1-butanone (NNK), N-Nitrosonornicotine (NNN), nitrosaminoaldehyde (NNAL), N-nitrosoanatabine (NAT) (Sugiyama et al., 2012; Wang et al., 2012; Yalcin and de la Monte, 2017). These compounds were metabolically activated to carcinogens by CYP2A6 in the liver or CYP2E1 expressed in pancreatic islets (Chowdhury et al., 2010; Kushida et al., 2000; Yuan et al., 2017). Thus, for people with CYP2A6 slow or poor metabolizing genotype, the hepatic first-pass metabolism of these compounds would decrease, resulting in higher systemic levels and greater exposure of these compounds in the pancreas islet. The enhancement levels of these compounds in pancreatic islet cells could be leading to metabolic activation by CYP2E1 and furthermore could lead to the development of pancreatic inflammation and apoptosis of insulinsecreting cells (Lees et al., 2004), finally, it would decrease the insulin secretion and the increased risk of development T2DM.

It was the first study to establish an association between the CYP2A6*4 allele gene among Javanese Indonesian T2DM patients, both active and passive smokers. This study is in line with other studies that reveal smoking as a modifiable and independent risk factor for T2DM, and the presence of the CYP2A6 * 4 allele gene in a person would increase the risk for developing of T2DM (Eze et al., 2014; Hackethal, 2015; Liu et al., 2011; Maddatu et al., 2017) . The other CYP2A6 allele gene that was common in Asia that was could decrease CYP2A6 activity was the CYP2A6*7 and CYP2A6*9 allele gene. Therefore, although in this study the CYP2A6*4 allele gene has not been identified in some non-smokers participants and the participant who has not a family history of DM, these participants may have the CYP2A6*7 or CYP2A6*9 allele gene. In future studies, it is necessary to identify these two alleles in T2DM patients.

According to Morimoto et al. (2013), Asians have a low ability to secrete insulin, so the results of this study may also be crucial for other Asian populations in reducing the development of T2DM. International Diabetes Federation has revealed that Indonesia was leading in the sixth country with the highest burden of diabetes mellitus in the world, there were saw that more than 10 million Indonesians had been suffering diabetes in 2017. The World Health Organization (WHO) has even predicted that more than 21 million Indonesians will develop diabetes by 2030. Primary Health Research Indonesia have reported that the prevalence of diabetes mellitus among Indonesia's adult population was $6.9 \%$ in 2013 and ascended to $8.5 \%$ in 2018 . Therefore, diabetes prevention and control were needed to reduce the incidence of diabetes mellitus and prevent its complications.

Unlike type 1 diabetes, there is currently no known way to prevent it. The development of T2DM in people with high risk could be prevented or delayed. Some studies have established that lifestyle modification, including quit smoking, can prevent or delay the onset of T2DM. Bergman et al. (2012) have revealed that insulin sensitivity to glucose will be returning to normal in a smoker who has stopped smoking. Some other studies have also reported that quitting smoking has been appeared to decrease the T2DM risk over time. It seems that the most important thing individuals living with T2DM could do to delay the onset of complications (Cho et al., 2009; Luo et al., 2013; Nilsson et al., 2014).

The CYP2A6 allele gene of smokers would affect whether a smoker would be easy to quit smoking or not. Some research has shown that smokers who have inactive alleles, especially CYP2A6*4, tend to be easier to stop smoking. It is due to their incapability to metabolize nicotine into cotinine (Ando et al., 2003; Fujieda et al., 2004; Minematsu et al., 2006). The other studies reported that the number of CPD of smokers who had a heterozygote genotype, including CYP2A6 * 
4, CYP2A6 * 7, CYP2A6 * 9, and CYP2A6 * 10 alleles were less than subjects who had a homozygous genotype (CYP2A6 *1/*1) (Chenoweth et al., 2013; O'Loughlin, 2004; Schoedel et al., 2004). According to our study, Javanese Indonesians have been categorizing as slow or poor metabolizers due to their belonging CYP2A6*4 allele gene, so they might be easier to stop their smoking. Therefore, the smoking cessation program should be encouraged for diabetes control and the prevention of diabetic complications among this population.

According to Padmawati et al. (2009), as many as 65\% of T2DM patients in Yogyakarta Special Region had a smoking history, even though some T2DM patients have continued to smoke without caring about the diabetic complication that will be occurring. It is due to that there was no integrated effort from health-care providers in Indonesia to encourage the smoking cessation program. Other than that, the smoking cessation program was not a routine part of diabetes counseling despite the risk of smoking to those with diabetes. Based on our study, we concluded that reducing the high smoking rate in Indonesia must be the principal goal of public health to prevent and control diabetes development, especially T2DM and its complications.

The Indonesian Consumers Foundation has stated that the non-smoking area was certainly needed to protect people from cigarette smoke so that they will not become passive smokers. Government Regulation of the Republic of Indonesia No. 188/Menkes/Pb/I/2011 and Number 7 of 2011 regarding The Guidelines Implementation of No-Smoking Areas was one of the government's efforts to reduce the air pollution caused by cigarette smoke. Through the application of this regulation, it has been expecting that the number of smokers in Indonesia would decrease, so that it would have an impact on reducing the number of diseases caused by cigarette smoke, including T2DM, both active and passive smokers. The no-smoking areas applied to the public facility, such as schools, work environments, community services, and public transportation areas, was one of the strategies that contribute to everyone's health. Yogyakarta Special Region was one of the provinces that have implemented this regulation in almost $80 \%$ of its regions, including Sleman. Furthermore, they also have had promotive and preventive programs through ongoing education of the smoking impact on children and adolescents in their school. The Environmental improvements and healthier behavior-changing are also carried out and planned systematically by all community components, such as the Healthy Living Community Movement (known as Gerakan Masyarakat Hidup Sehat/GERMAS) and Integrated Service Center (known as Pos Pembinaan Terpadu/POSBINDU), to realizing a better degree of public health. In these public centers, health screening has also early carried out to detect the behavioral risk factors that caused some non-communicable disease, including diabetes. Unfortunately, until now, there are not many people using this health facility, therefore the diabetes prevention in this area has not been optimally implemented, causing a high number of diabetics in this area.

\section{Study Limitations}

It was a cross-sectional study. The smoking status information has just determined on selfassessment from the subject. Furthermore, there were not biological validation methods to confirm and report the smoking status, including expired air carbon monoxide or saliva/plasma/urine cotinine concentrations. In this study, there were also confounding factors that have not been anticipating, given the possible link between smoking and alcohol consumption, and drinking coffee that might also influence glucose blood levels.

\section{CONCLUSIONS}

From this study, we define that smoking would increase the potential development for suffering T2DM, neither active nor passive smokers. We have also described that the CYP2A6*4 high frequency has been founding among Javanese Indonesian T2DM patients causing they have more easily get T2DM. Thus, the principal strategies for reducing the number of diabetes incidences, neither active nor passive smokers, and preventing the development of diabetes complications were educating the people to quit smoking and encourage smoking cessation programs. 


\section{ACKNOWLEDGEMENT}

We would like to thank Lembaga Penelitian dan Pengabdian Kepada Masyarakat Sanata Dharma University funding this study.

\section{REFERENCES}

Abdullah, M., \& Mansour, A. (2020). The prevalence and risk factors of type 2 diabetes mellitus ( DMT2 ) in a semi-urban Saudi population. International Journal of Environmental Research and Public Health, 17(1), 1-8.https:/doi.org/10.3390/ijerph17010007

ADA. (2014). Standards of Medical Care in Diabetes- 2014. Diabetes Care, 37, S14-S80. https://doi.org/10.2337/dc14-S014

Agbogli, H. K., \& Annan, R. (2017). Prevalence and risk factors of diabetes mellitus among the inhabitants of kumasi metropolis. Archives of Clinical and Biomedical Research, 1(4), 224-234. https://doi.org/10.26502/acbr.50170025

Alva, M. L., Hoerger, T. J., Zhang, P., \& Gregg, E. W. (2017). Identifying risk for type 2 diabetes in different age cohorts: does one size fit all? Diabetes Research and Care, 1-7. https://doi.org/10.1136/bmjdrc-2017-000447

Ando, M., Hamajima, N., Ariyoshi, N., Kamataki, T., \& Matsuo, K. (2003). Original association adults article of CYP2A6 gene deletion with cigarette smoking status in Japanese and Yoshiyuki Ohno . 1. Journal of Epidemiology, 13(3), 176-181

Asiimwe, D., Mauti, G. O., \& Kiconco, R. (2020). Prevalence and risk factors associated with type 2 diabetes in elderly patients aged 45-80 years at kanungu district, 2020

Association, A. D. (2011). Executive summary: standards of medical care in diabetes-2011. Diabetes Care, 34(Supplement 1), S4-S10. https://doi.org/10.2337/dc11-S004

Bajaj, M. (2012). Nicotine and insulin resistance: when the smoke clears. Diabetes, 61(12), 30783080. https://doi.org/10.2337/db12-1100

Barber, S., Adioetomo, S. M., Ahsan, A., \& Setyonaluri, D. (2008). Tobacco Economics in Indonesia. Paris: The Union

Bergman, B. C., Perreault, L., Hunerdosse, D., Kerege, A., Playdon, M., Samek, A. M., \& Eckel, R. H. (2012). Novel and reversible mechanisms of smoking-induced insulin resistance in humans. Diabetes, 61(12), 3156-3166. https://doi.org/10.2337/db12-0418

Binh, T. Q., \& Nhung, B. T. (2015). Prevalence and risk factors of type 2 diabetes in middle-aged women in Northern Vietnam. International Journal of Diabetes in Developing Countries, 36(2), 1-8. https://doi.org/10.1007/s13410-015-0372-6

Borowitz, J. L., \& Isom, G. E. (2008). Nicotine and type 2 diabetes. Toxicological Sciences, 103(2), 225-227. https://doi.org/10.1093/toxsci/kfn050

Buell, C., Kermah, D., \& Davidson, M. B. (2007). Utility of A1C for diabetes screening in the 1999 2004 NHANES population. Diabetes Care, 30(9), 2233-2235. https://doi.org/10.2337/dc07-0585

Campagna, D., Alamo, A., Pino, A. Di, Russo, C., Calogero, A. E., Purrello, F., \& Polosa, R. (2019). Smoking and diabetes : dangerous liaisons and confusing relationships. Diabetology \& Metabolic Syndrome, 1-12. https://doi.org/10.1186/s13098-019-0482-2

Cederberg, H., \& Stan, A. (2014). Family history of type 2 diabetes increases the risk of both obesity and its complications: is type 2 diabetes a disease of inappropriate lipid storage? https://doi.org/10.1111/joim.12289

Chang, S. A. (2012). Smoking and type 2 diabetes mellitus. Diabetes \& Metabolism Journal, 36(6), 399-403. https://doi.org/10.4093/dmj.2012.36.6.399

Chenoweth, M. J., O’Loughlin, J., Sylvestre, M.-P., \& Tyndale, R. F. (2013). CYP2A6 slow nicotine metabolism is associated with increased quitting by adolescent smokers. Pharmacogenetics and Genomics, 23(4), 232-235. https://doi.org/10.1097/FPC.0b013e32835f834d

Cho, N. H., Chan, J. C. N., Jang, H. C., Lim, S., Kim, H. L., \& Choi, S. H. (2009). Cigarette smoking is An independent risk factor for type 2 Diabetes : a four-year community-based prospective 
study. J. Clin. Endocrinol., 71, 679-685. https://doi.org/10.1111/j.1365-2265.2009.03586.x

Chowdhury, G., Calcutt, M. W., \& Guengerich, F. P. (2010). Oxidation of N-Nitrosoalkylamines by human cytochrome P450 2A6: sequential oxidation to aldehydes and carboxylic acids and analysis of reaction steps. The Journal of Biological Chemistry, 285(11), 8031-8044. https://doi.org/10.1074/jbc.M109.088039

Cornier, M., Donahoo, W. T., Pereira, R., Gurevich, I., Westergren, R., Enerback, S., ... Draznin, B. (2005). Insulin sensitivity determines the effectiveness of dietary macronutrient composition on weight loss in obese women. Obesity Research, 13(4), 703-709

Eze, I. C., Schaffner, E., Zemp, E., Eckardstein, A. Von, Turk, A., Bettschart, R., ... Probst-hensch, N. (2014). Environmental tobacco smoke exposure and diabetes in adult never-smokers. Environmental Health, (13), 1-9

Fujieda, M., Yamazaki, H., Saito, T., Kiyotani, K., Gyamfi, M. A., Sakurai, M., ... Kamataki, T. (2004). Evaluation of CYP2A6 genetic polymorphisms as determinants of smoking behavior and tobacco-related lung cancer risk in male Japanese smokers. Carcinogenesis, 25(12), 2451-2458. https://doi.org/10.1093/carcin/bgh258

Hackethal, V. (2015). Passive Smoking Increases Risk for Type 2 Diabetes, 9-11.

Heatherton, T. . F., Kozlowki, L., Frecker, R. C., \& Fagerstrom, K. ar.-O. (1991). The fagerstrom test for nicotine dependence: a revision of the fagerstrom tolerance questionnaire, 86(9), 1119-1127. https://doi.org/10.1111/j.1360-0443.1991.tb01879.x

Hilawe, E. H., Yatsuya, H., Li, Y., Uemura, M., Wang, C., Chiang, C., ... Aoyama, A. (2015). Smoking and Diabetes: Is the Association Mediated by Adiponectin, Leptin, or C-reactive Protein ?, 25(2), 99-109. https://doi.org/10.2188/jea.JE20140055

Hong, J. W., Ku, C. R., Noh, J. H., Ko, K. S., Rhee, B. D., \& Kim, D. J. (2018). Association between self-reported smoking and hemoglobin A1c in a Korean population without diabetes: the $2011-$ 2012 Korean national health and nutrition examination survey. PLOS ONE, 10(5), 1-8

Hu, F. B. (2011). Globalization of Diabetes The role of diet, lifestyle , and genes. Diabetes Care, 34, 1249-1257. https://doi.org/10.2337/dc11-0442

Jee, S.H.; Foong, A.W.; Hur, N.W.; Samet, J. M. (2010). Smoking and risk for diabetes incidence. Diabetes Care, 33(12), 2567-2572. https://doi.org/10.2337/dc10-0261

Kirkman, M.S; Briscoe, V.J; Clark, N.; Florez, H.; Haas, L.B.; Halter, J.B.; Huang, E.S.; Korytkwoski, M.T., Munshi, M.N.; Odegard, P.S.; Pratley, R.E.; Swift, C. S. (2012). Diabetes in Older Adults. Diabetes Care, 35(10), 2650-2664. https://doi.org/10.2337/dc12-1801

Kowall, B., Rathmann, W., Strassburger, K., Heier, M., Holle, R., Thorand, B., ... Meisinger, C. (2010). Association of passive and active smoking with incident type 2 diabetes mellitus in the elderly population: the KORA S4/F4 cohort study. European Journal of Epidemiology, 25(6), 393-402. https://doi.org/10.1007/s10654-010-9452-6

Kushida, H., Fujita, K., Suzuki, A., Yamada, M., Endo, T., Nohmi, T., \& Kamataki, T. (2000). Metabolic activation of $\mathrm{N}$-alkylnitrosamines in genetically engineered Salmonella typhimurium expressing CYP2E1 or CYP2A6 together with human NADPH-cytochrome P450 reductase. Carcinogenesis, 21(6), 1227-1232. https://doi.org/10.1093/carcin/21.6.1227

Lees, D. J., Barnett, Y. A., \& Barnett, C. R. (2004). DNA damage and cytotoxicity in pancreatic b cells expressing human CYP2E1. Biochemical Pharmacology, 68, 523-530. https://doi.org/10.1016/j.bcp.2004.04.008

Liu, S., Manson, J. E., Stampfer, M. J., Hu, F. B., Giovannucci, E., Colditz, G. A., ... Willett, W. C. (2000). A Prospective Study of Whole-Grain Intake and Risk of Type 2 Diabetes Mellitus in US Women. American Journal of Public Health, 90(9), 1409-1415

Liu, T., Chen, W.-Q., David, S. P., Tyndale, R. F., Wang, H., Chen, Y.-M., ... Ling, W.-H. (2011). Interaction between heavy smoking and CYP2A6 genotypes on type 2 diabetes and its possible pathways. European Journal of Endocrinology / European Federation of Endocrine Societies, 165(6), 961-967. https://doi.org/10.1530/EJE-11-0596

Liu, X., Bragg, F., Yang, L., Kartsonaki, C., Guo, Y., Du, H., ... Wang, K. (2018). Articles Smoking 
and smoking cessation in relation to risk of diabetes in Chinese men and women : a 9-year prospective study of 0 . 5 million people. Lancet Public Health, 3, 167-176. https://doi.org/10.1016/S2468-2667(18)30026-4

Luo, J., Rossouw, J., Tong, E., Giovino, G. A., Lee, C. C., Chen, C., ... Margolis, K. L. (2013). Original contribution smoking and diabetes : does the increased risk ever go away ?, 178(6), 937945. https://doi.org/10.1093/aje/kwt071

Maddatu, J., Anderson-baucum, E., Evans-molina, C., \& Physiology, I. (2017). Smoking and the Risk of Type 2 Diabetes. Transl Res., (184), 101-107. https://doi.org/10.1016/j.trsl.2017.02.004.Smoking

Mary, G., Carolin, H., Naomi, H., Helen, O., Lorraine, O., Anna, C., \& Louisa, E. (2014). Adult obesity and type 2 diabetes. London: Public Health England

Minematsu, N., Nakamura, H., Furuuchi, M., Nakajima, T., Takahashi, S., Tateno, H., \& Ishizaka, A. (2006). Limitation of cigarette consumption by CYP2A6*4, *7 and *9 polymorphisms. The European Respiratory Journal, 27(2), 289-292. https://doi.org/10.1183/09031936.06.00056305

Morimoto, A., Tatsumi, Y., Deura, K., Mizuno, S., Ohno, Y., \& Watanabe, S. (2013). Impact of cigarette smoking on impaired insulin secretion and insulin resistance in Japanese men: The Saku Study. Journal of Diabetes Investigation, 4(3), 274-280. https://doi.org/10.1111/jdi.12019

Mwenifumbo, J. C., Al Koudsi, N., Ho, M. K., Zhou, Q., Hoffmann, E. B., Sellers, E. M., \& Tyndale, R. F. (2008). Novel and established CYP2A6 alleles impair in vivo nicotine metabolism in a population of Black African descent. Human Mutation, 29(5), 679-688. https://doi.org/10.1002/humu.20698

Nguyen, Q. M., Xu, J.-H., Chen, W., Srinivasan, S. R., \& Berenson, G. S. (2012). Correlates of age onset of type 2 diabetes among relatively young black and white adults in a community. Diabetes Care, 35, 1341-1246. https://doi.org/10.2337/dc11-1818

Nilsson, P. M., Ardanaz, E., Gavrila, D., \& Agudo, A. (2014). Smoking and long-term risk of type 2 diabetes: The EPIC- interAct Study in European Populations. Diabetes Care, 37, 3164-3171. https://doi.org/10.2337/dc14-1020

O'Loughlin, J. (2004). Genetically decreased CYP2A6 and the risk of tobacco dependence: a prospective study of novice smokers. Tobacco Control, 13(4), 422-428. https://doi.org/10.1136/tc.2003.007070

Padmawati, R. S., Ng, N., Prabandari, Y. S., \& Nichter, M. (2009). Smoking among diabetes patients in Yogyakarta, Indonesia : cessation efforts are urgently needed. Trop. Med. Int. Health, 14(4), 412-419. https://doi.org/10.1111/j.1365-3156.2009.02241.x

Patramurti, C., \& Fenty, F. (2020). Association of smoking behaviour and glycohemoglobine levels among adults javanese Indonesian smokers, 11-13

Patramurti, C., Nurrochmad, A., Martono, S., Science, P., Mada, G., \& Chemistry, P. (2015). Poymorphism of Cytochrome P450 2A6 ( CYP2A6 * 1 AND CYP2A6 * 4 ) among Javaneses Indonesia Smoker and Non Smoker. MFI, 26(1), 11-19. https://doi.org/10.14499/indonesianjpharm26iss1pp11

R.I., K. K. (2018a). Hari diabetes sedunia tahun 2018. Jakarta: Departemen Kesehatan R.I

R.I., K. K. (2018b). Hasil utama riskesdas 2018. Jakarta: Badan Penelitian dan Pengembangan Kesehatan.

Sakurai, M., Nakamura, K., Miura, K., Takamura, T., Yoshita, K., \& Sasaki, S. (2013). Family history of diabetes, lifestyle factors, and the 7-year incident risk of type 2 diabetes mellitus in middleaged Japanese men and women, 4(3), 261-268. https://doi.org/10.1111/jdi.12033

Sattar, N., Rawshani, A., Franzén, S., Rawshani, A., Svensson, A.-M., Rosengren, A., ... Gudbjörnsdottir, S. (2019). Age at diagnosis of type 2 diabetes mellitus and associations with cardiovascular and mortality risks. Circulation, 2228-2237. https://doi.org/10.1161/CIRCULATIONAHA.118.037885

Schoedel, K. a, Hoffmann, E. B., Rao, Y., Sellers, E. M., \& Tyndale, R. F. (2004). Ethnic variation in 
CYP2A6 and association of genetically slow nicotine metabolism and smoking in adult Caucasians. Pharmacogenetics, 14(9), 615-626. https://doi.org/10.1097/00008571-200409000$\underline{00006}$

Schulze, M. B., Manson, J. E., Ludwig, D. S., Colditz, G. A., Stampfer, M. J., \& Willett, W. C. (2015). and incidence of type 2 diabetes in young and middle-aged women, 292(8), 927-934

Scott, R. A., Langenberg, C., Sharp, S. J., Franks, P. W., Rolandsson, O., \& Drogan, D. (2014)

Europe PMC funders group the link between family history and risk of type 2 diabetes is not explained by anthropometric, lifestyle or genetic risk factors : the EPIC-InterAct study, 56(1), 60-69. https://doi.org/10.1007/s00125-012-2715-x

Sugiyama, K., Inaba, Y., Ohkubo, T., Uchiyama, S., Takagi, Y., \& Kunugita, N. (2012). Determination of tobacco-specific N'-nitrosamines in mainstream smoke from Japanese cigarettes. Nihon Eiseigaku Zasshi. Japanese Journal of Hygiene, 67(3), 423-430

Tanner, J., \& Tyndale, R. F. (2017). Variation in CYP2A6 activity and personalized medicine, 6, 129. https://doi.org/10.3390/jpm7040018

Wang, J., Xu, Y., Li, J., Sun, X., Wang, L.-P., \& Ji, W.-Y. (2012). The tobacco-specific carcinogen NNK induces DNA methyltransferase 1 accumulation in laryngeal carcinoma. Oral Oncology, 48(6), 541-546. https://doi.org/10.1016/j.oraloncology.2012.01.007

Wang, Y., Ji, J., Liu, Y., Deng, X., \& He, Q. (2013). Passive Smoking and Risk of Type 2 Diabetes : A Meta- Analysis of Prospective Cohort Studies. Plos One, 8(7), 1-6. https://doi.org/10.1371/journal.pone.0069915

Wei, X., Meng, E., \& Yu, S. (2014). A meta-analysis of passive smoking and risk of developing Type 2 Diabetes Mellitus. Diabetes Research and Clinical Practice, 107(1), 9-14. https://doi.org/10.1016/j.diabres.2014.09.019

Xie, X., Liu, Q., Wu, J., \& Wakui, M. (2009). Impact of cigarette smoking in type 2 diabetes development. Acta Pharmacologica Sinica, 30(6), 784-787. https://doi.org/10.1038/aps.2009.49

Yalcin, E.; de la Monte, S. (2017). Tobacco nitrosamines as culprits in disease: mechanisms reviewed. J Physiol Bhiochem, 72(1), 107-120. https://doi.org/10.1007/s13105-016-0465-9

Yeh, H.-C., Duncan, B. B., Schmidt, M. I., Wang, N.-Y., \& Brancati, F. L. (2010). Smoking, smoking cessation, and risk for type 2 diabetes mellitus a cohort study. Annals of Internal Medicine, 152(1), 10-17. https://doi.org/10.7326/0003-4819-152-1-201001050-00005

Yuan, J., Nelson, H. H., Carmella, S. G., Wang, R., Kuriger-laber, J., Jin, A., ... Murphy, S. E. (2017). CYP2A6 genetic polymorphisms and biomarkers of tobacco smoke constituents in relation to risk of lung cancer in the Singapore Chinese Health Study. Carcinogenesis, 38(4), 411-418. https://doi.org/10.1093/carcin/bgx012

Zhao, Y., Song, C., Ma, X., Ma, X., Wang, Q., Ji, H., ... Qin, G. (2017). Synergistic effect of family history of diabetes and dietary habits on the risk of type 2 diabetes in central China, 2017

Zheng, R.; Marquez, P.V.; Ahsan, A.; Wang, Y.; Hu, X. (2018). Affordability in Indonesia : 20022017. Washington, D.C.: The World Bank Group. https://doi.org/10.1596/30027 
